Association for Information Systems AIS Electronic Library (AISeL)

BLED 2006 Proceedings

BLED Proceedings

2006

\title{
Mobile Service Bundles: The Example of Navigation Services
}

Timber Haaker

Telematica Instituut, The Netherlands, timber.haaker@telin.nl

Henny de Vos

Telematica Instituut, The Netherlands, henny.devos@telin.nl

Harry Bouwman

Delft University of Technology, The Netherlands, w.a.g.a.bouwman@tudelft.nl

Follow this and additional works at: http://aisel.aisnet.org/bled2006

\section{Recommended Citation}

Haaker, Timber; Vos, Henny de; and Bouwman, Harry, "Mobile Service Bundles: The Example of Navigation Services" (2006). BLED 2006 Proceedings. 24.

http://aisel.aisnet.org/bled2006/24

This material is brought to you by the BLED Proceedings at AIS Electronic Library (AISeL). It has been accepted for inclusion in BLED 2006

Proceedings by an authorized administrator of AIS Electronic Library (AISeL). For more information, please contact elibrary@aisnet.org. 


\title{
$19^{\text {th }}$ Bled eConference
}

eValues

Bled, Slovenia, June 5 - 7, 2006

\section{Mobile Service Bundles: The Example of Navigation Services ${ }^{1}$}

\author{
Timber Haaker \& Henny de Vos
}

Telematica Instituut, The Netherlands

timber.haaker@telin.nl/henny.devos@telin.nl

\section{Harry Bouwman}

Delft University of Technology, The Netherlands w.a.g.a.bouwman@tbm.tudelft.nl

\begin{abstract}
In this paper we explore which bundles of services are attractive to users. We look specifically into bundle composition with navigation services as core, and travel and entertainment related services as complementary services. Pricing is an important criterion as well. We use conjoint measurement as a tool to assess which combination of services and price is the most attractive for users. We find that enhanced services, i.e. services that reinforce the functionality of the core navigation service are more relevant than supplementary services. Traffic information, safety alerts and parking support have positive utilities. However, pricing has a higher predictive value.
\end{abstract}

Keywords: Mobile services, navigation, service bundling, pricing, conjoint

\section{Introduction}

Research in customer needs and behaviour concerning $3 \mathrm{G}+$ mobile service bundles is hindered by the fact that respondents have little or no idea about the specific characteristics of service bundles that are not yet available. Consumer decisions are not only related to the adoption of these specific service bundles but also to concerns about

1 This article is based on the work of a large number of researchers from the Telematica Instituut and Delft University of Technology. The work was carried out within the Freeband project FrUX. We gratefully acknowledge our colleagues contributions. 
their potential use and expected benefits. Mobile services bundles can be delivered via different networks on a number of alternative devices in varying situations and for varying prices. So any final decision about adoption and use has to take characteristics of devices, networks, service bundles and price-levels into account, as well as the context and characteristics of users. In this paper we specifically examine the user's perception of the utility of mobile service bundles in the area of personal navigation.

Navigation services are among the most successful mobile services and Tom Tom is one of the most successful providers. The company offers, for instance, a user-centric navigation information service with real-time value-added information services for users of PDAs, mobile phones and stand alone navigation systems. In addition, Tom Tom has recently started offering value-added services (like map updates, real-time weather, traffic, and safety camera information services) under the name Tom Tom PLUS Services. Its services are directed at the mass consumer market. Tom Tom makes money by selling (updates on) navigation software (fixed price), stand alone navigation services (fixed price), and value-added (subscription-based) services. The company's main costs are product and service development, and marketing. The navigation technology that is used combines GPS, localisation and map technology, together with GPRS and/or UMTS networks.

Companies like Tom Tom have been important drivers in making personal navigation a mainstream consumer service. Until recently built-in and dedicated hand-held navigation systems dominated the consumer market, but more and more software becomes available for smart-phones or PDA's as navigators, as the above-mentioned example illustrates. With broadband wireless networks becoming increasingly available, off-board personal navigation is emerging. Off-board navigation systems receive navigation information via real-time data transfers over a wireless network and provide up-to-the-minute routing directions (Schlesinger, 2003). Navigation systems are rapidly becoming a commodity with retail prices and profits moving downwards. To attract and retain customers providers have to differentiate by combining the core navigation service with additional functionalities.

In this paper we start from service bundling theory and investigate what kind of services will provide added value to core navigation. We look at this in relation to bundle pricing. In the next section we discuss the service bundle literature, after which we address the research approach and the design, and subsequently present our main findings. In the final section we discuss the results and draw conclusions.

\section{Service Bundles and Pricing}

Product bundling has a long history. Bundling is the sale of two or more separate products or services in one package for a special price (Stremersch \& Tellis, 2002; Guiltinan, 1987; Shapiro \& Varian, 1999). Before we discuss product bundling further, we have to distinguish between various types of products. Kotler (1999) has defined three levels of product: core product, actual product and augmented product. Core products include the core benefit or service. Actual product includes packaging, brand name, quality level, design and features. Augmented products includes installation, delivery and credit, warranty and after sales services. Bundling of core products with other functional complementary products is a common and widespread practise. The best-known example is Microsoft Office, in which a word processor, a spreadsheet, a database and a presentation tool have been bundled.

Companies use bundling to pursue price discrimination (Adams \& Yellen, 1976), increase sales (Zhu \& McQuarrie, 2003), promote customer lock-in and create entry barriers (Benett \& Robson, 2001). Although bundling strategies have been around for quite some time, little is as yet known about what constitutes a successful bundle. Spiller \& Zelner 
(1997) assume that companies tend to bundle their products in response to some kind of technological or regulatory shock. Such a shock is argued to make products complementary in new ways, the result being that there is additional demand for each of the products that did not previously exist. The interdependency between products is critical cases where products depend directly on each other with regard to their use, as is the case in many computer, information and telecommunication services. The use of software is impossible without hardware and vice versa. Bundling of information goods, such as software, is omnipresent in today's business environment, and a well-known phenomenon in the Telecommunication Industry. Packages in which telephony services are combined with wireless and Internet services are common. In Europe bundling of mobile services with 'an almost for free' handset is everyday practice. The goal of Telecom Operators is straightforward: increasing revenue, lower churn-rates and improve margins.

Some research into service bundling focuses mainly on bundling services with auxiliary or support services (Simons \& Bouwman, 2004), and less on complementary services that are equal to the core service, as we are interested in here. Normann (2001) discusses (un)bundling in a development towards a need-oriented matching between activities of customers and suppliers. Mourdoukoutas \& Mourdoukoutas (2004) consider bundling in a semi-global economy in which commodity products are bundled with local services to achieve local product differentiation. Chiasson (1999) presents a model for designing bundles. He argues that bundling requires a formal process to structure the economic and strategic value of the bundle and to deliver it to the market. Issues he discusses are the strategic purpose of the service bundle, in terms of market and product strategy, and the functional objectives. These functional objectives are discussed in relation to channels, marketing, support systems, billing and telecommunication network requirements. If a bundle is to be marketed quickly, to be profitable and be consistent, trade-off decisions in the design stage are crucially important, for instance with regard to the bundle composition (Bouwman et al., 2005).

Bundle composition refers to the services and products that are included in the bundle. Services not only have an intrinsic value, e.g. expressed by their core benefit, but also a relative value that depends on their role within the bundle. Services or products may be mutually reinforcing (e.g. communication and presence information), complementary (e.g. mobile phone and subscription), unrelated (e.g. ring tone and weather information service) or competing (e.g. ring tone service A and B). Guiltinan (1987) argues that services are often interdependent in demand and Harlam et al. (1995) suggest that people may be more likely to purchase bundles composed of complements than bundles of similar or unrelated products. In the case of service bundles in the navigation domain addons that build on the initial core, like integrated traffic information, may enhance the initial service value. We will call these enhanced services: enhanced services are directly related to the core service. Unrelated supplementary services extend the initial benefits in new directions, i.e. location-based advertising in combination with navigation services. Related to the arguments of Guiltinan (1987) and Harlam (1995) we hypothesize that

H 1 People are more likely to buy enhanced services than supplementary services.

In addition to bundle composition, pricing of bundles is also an important issue. The price of a bundle is usually less than the sum of its components. A bundle of two products is a way of offering one product for a price that is smaller than its stand-alone price. However, it may be clear that companies are not going to offer a bundled product in combination with a discount when customers would purchase that product anyway. Price discrimination is an important issue when discussing bundle pricing. We hypothesize that 
H 2 Bundle price discount has a positive effect on the likelihood that users will purchase.

Consumer theory relates preferences, indifference curves and budget constraints to consumer demand curves (Green, 1976). Budget considerations may therefore be an important constraint in people's evaluations of service bundles. Given that bundle size is closely related to bundle price, the number of services included in the bundle may have a negative impact on the likelihood that users will purchase. Focusing on a limited number of services in a bundling strategy may be smarter than bundling a large number of fairly heterogeneous enhanced and supplementary services. We hypothesize that

H 3 Bundle size has a negative effect on the likelihood that users will purchase.

Of course there are some intermediating factors that may influence the relationship between bundle composition, bundle size, bundle price discount and purchase intent outlined above. A great deal may depend on the type of trip: business or pleasure, and personal characteristics, like attitude toward technology, and type of traveler (times traveling per week, different destinations).

\section{Research Approach}

Traditional research methods are not really suitable for capturing this type of complexity that plays a role in the decision to purchase a certain service bundle at a given price. The external validity of survey studies on the adoption and use of service bundles for a specific price in general proved limited. Experimental studies are also of little value because they are not directed towards extrapolating results towards a broader population, and because they only address a limited set of variables. And although qualitative research offers a wealth of information, it has little predictive value. All this means that, if we are to investigate the complex decision-making processes surrounding service bundles that have yet to be on offer, we need to use an alternative research method.

Based on earlier research (Van de Wijngaert, 1996, 1999; Bouwman \& Van de Wijngaert, 2002, 2003; Bouwman 2004), we know that factorial survey is a valuable alternative, because it integrates the strict factorial design and the attribute concept of orthogonality. The factorial approach is based on experimental research and combined with the external validity and richness of detail provided by survey research. This allows us to bridge the gap between the experimental and the real world. "Factorial surveys more faithfully capture the complexity of real life and the conditions of real human choices and judgments and at the same time provide the ability to identify clearly the separate influences on the many factors that go into such judgments and choices" (Rossi \& Anderson, 1982, p. 16). It has the more or less unobtrusive character associated with qualitative research, in that it provides respondents with detailed descriptions of daily life practices, taking both abstract context and day-to-day situations in account. As we became more involved in factorial design, vignette studies or policy-capturing, we noticed that similar, yet more or less unrelated approaches to marketing and product development research have been around for some time. Conjoint measurement especially has received great deal of attention in these domains. It would appear that, although policy capturing and conjoint measurement are rather similar, they developed independently from each other. The basic idea is to present people with contrived hypothetical situations. These situations, scenarios, vignettes or conjoints, are developed by combining individual characteristics into a conceptual continuity. 


\begin{abstract}
Although one would expect measurement approaches to be widely used specifically in the domain of new media, information and communication technology, software and service development factorial surveys, policy capturing studies and conjoint, their use in relation to new media is rather limited. Martocchio, Webster and Baker (1993), Webster and Trevino (1995), Van de Wijngaert (1996, 1999), Bouwman \& Van de Wijngaert (2002, 2003) and Zubey, Wagner \& Otto (2002) use these research approaches in discussing media choice models, information needs in relation to media choice, e-commerce channel preferences, and Voice over IP. Furthermore, there are some studies in the area of next generation mobile services. Kim (2004), for instance, looks at the next generation mobile services, i.e. mobile Internet services, video telephony and global roaming services in relation to their price. Bouwman (2004) discusses which 3rd generation mobile entertainment and information services are preferred by users of mobile telephones and what the underlying context and situational variables are that influence their choices. Brodt \& Heitmann (2004) looks into one specific mobile entertainment service, i.e. video clip multicasting services via GPRS. Köhne, Totz \& Wehmeyer (2003) used conjoint measurement to establish consumer preferences for location-based mobile tourist services. These approaches are directed more towards service supply. When it comes to the more user-oriented studies, Pagani (2004) looks at usefulness, ease of use, price and speed of use, while Kleijnen et al. (2004) discuss perceived risk, relative advantage, compatibility, level of complexity, communicability, critical mass, navigation and payment options.
\end{abstract}

\title{
4. Research Design
}

The research design process follows the standard procedure for conjoint surveys (Green \& Srinivasan, 1978). The first step concerns attribute selection. The bundles that we examined are composed of a set of services added on to basic navigation. Each add-on service is considered a bundle attribute with two levels, i.e. either it is included in the bundle or it is not. We selected the potentially valuable add-on services on the basis of current navigation practices, and on an identification of existing and emerging services surrounding basic navigation. A navigation system typically supports users in going from some current position A (e.g. home) to a destination B via a short and/or fast route. The drive itself and the route that is followed may be labeled $C$ (see Figure 1). The core navigation service and the potential add-on services may be mapped onto either A, B or C. The navigation experience itself (C) is delivered by the core navigation service, which may be enhanced by adding services like traffic information, points of interest, safety alerts etc. Services that take place at or concern locations A and B enhance or complement the navigation experience. Weather forecasts for B, parking information or even parking space reservation are services that are focused on the destination B. Similarly, community services related to navigation, e.g. sharing of interesting routes, or creating and uploading routes to the navigation system before the actual drive, focus on the point of departure. Finally, supplementary services like personalization, location based advertising or entertainment services, i.e. $\mathrm{mp} 3$ player integrated with the navigation device, or a service for the 'back seat', may enhance the actual driving from A to B, by trying to make it as pleasant or convenient as possible.

In addition to regular updates of the services, we distinguish nine services that are either included in the bundle or not:

Up to date service ( $€ 3,-$,

(2) Travel preparation ( €2,-)

(3) Navigation club ( €1,-),

(4) Personalization of the services ( $€ 2,-)$, 
(5) Traffic information (€2,-),

(6) Safety alerts ( $€ 2,-)$,

(7) Location-based advertising ( €1,-),

(8) Audio-books ( €2,-),

(9) Parking assistance ( €2,-),

Enhanced services are all the services directly related to traveling, navigation, parking et cetera, while personalization, navigation club, location-based advertising and audio books can be considered supplementary services. We also included a three-level price attribute that describes a bundle price discount on the assumed sum of individual service prices. The assumed prices for the individual services were derived or estimated from current service offerings. The assumed price for each add-on service is low ( $25 \%$ discount), regular or high (25\% surcharge). Attributes and levels were tested for soundness with potential respondents.

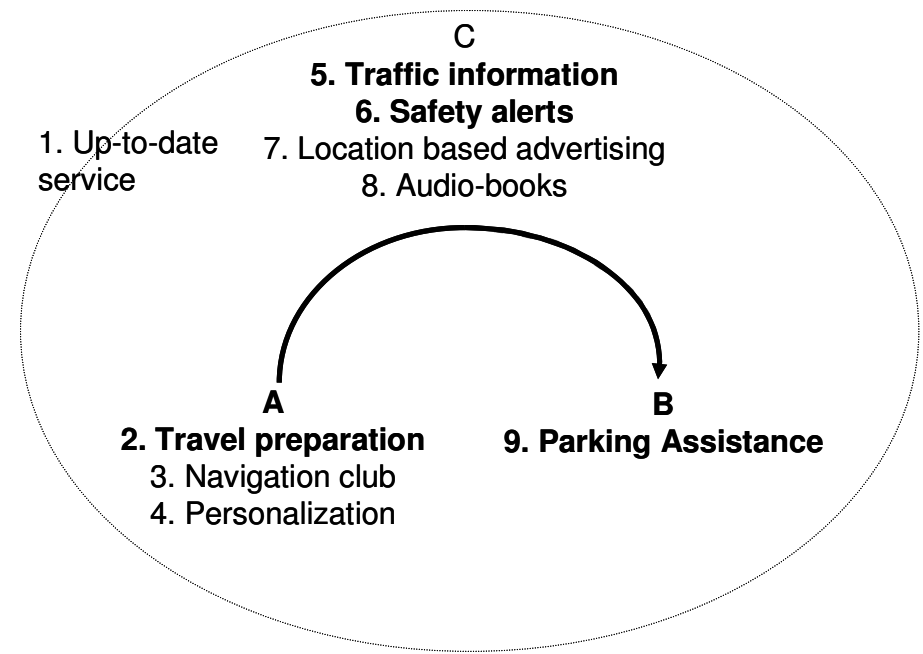

Figure 1: Reference points for complementary services.

We used a traditional conjoint analysis approach in which respondents rated their purchase intention for specific add-on service bundles on a 7-point scale. Respondents were presented with full profile vignettes using a web-based survey tool. The vignettes showed the bundle composition, i.e. the add-on services included in the bundle, as well as the bundle price. Each service is assumed to be offered on a subscription basis. The bundle price is calculated from the sum of the assumed subscription prices for the individual services, for which, depending on the bundle price discount level, a discount is given. Figure 2 illustrates how the bundle was presented to the respondents.

In a full profile conjoint analysis all possible vignettes would be presented to the respondents. In total this would be $29 * 3=1536$ (i.e. nine services that are either included or excluded and three price levels). By using an orthogonal design we were able to reduce the number of vignettes to 16 and derive reliable estimates for the parameters. In an orthogonal design the attributes, i.e. the add-on services, are evenly distributed among the vignettes. Rating results were analyzed with the aid of SPSS. The part worth utilities for individual respondents were calculated using ordinary least squares. The individual part worth utilities were used to classify subjects with a hierarchical cluster analysis. 


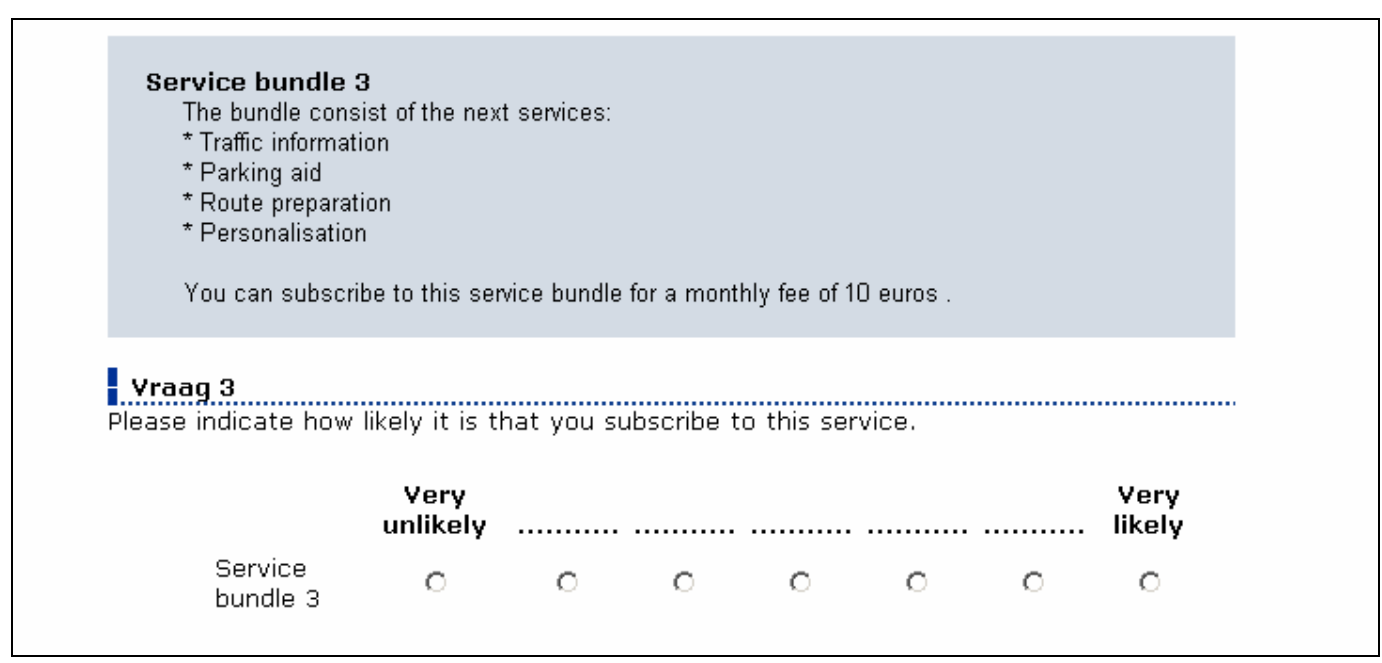

Figure 2: Example of vignette as used in the questionnaire.

We also included questions regarding age, gender, income, education, and attitude towards mobile services and navigation services (availability of mobile phone, type of network, current use of mobile services, familiarity with navigation services, reason for traveling and familiarity of destination).

The questionnaire was completed by 156 of the 350 people we invited to participate: a response of $44 \%$. These respondents are part of a national panel in the Netherlands. We only asked people who owned a car and traveled at least $3000 \mathrm{~km}$ a year to participate in the survey. Thirty-nine percent of the respondents were female, $61 \%$ were male respondents; $29 \%$ was under 30, 33\% between 30 and 39, 24\% was between 40 and 49 years of age and the remaining $14 \%$ was above 50 . Only $11 \%$ of the respondents indicated that they never used SMS. Of the respondents $36 \%$ pointed out that they occasionally used SMS information services and 33\% said that they incidentally used their mobile phone for other services, like downloading ring tones. Of the respondents, $29 \%$ indicated that in general they are unfamiliar with the destination they travel to, whereas for $71 \%$ the destination is well-known. Of the respondents $31 \%$ already used a navigation system. Of the remaining $69 \%, 72 \%$ indicated that they are familiar with the possibilities of navigation systems. It would appear that personal navigation has become a common enough service to allow people to express an opinion, regardless of whether they use the service themselves or not. Furthermore, there is enough heterogeneity in the respondent group to ensure a balanced view on purchase intent for (mobile) navigation services.

We eliminated a further 49 respondents from our population, who all indicated they had no intention under any circumstances to ever consider subscribing to the service bundles with which we presented them, presumably either because they were not interested in the services anyway, or because they thought the services were too expensive.

\section{Results}

Table 1 presents the results of the analysis of the part worth utilities of the various attributes and levels on an aggregated level, as well as an indication of the relative importance of the bundle attributes. The relative importance is a measure for an attribute's power to induce a variation of preferences. 
Table 1: Average importance and calculated part worth utilities

\begin{tabular}{|c|c|c|c|c|}
\hline \multirow[b]{2}{*}{ Service } & \multirow[b]{2}{*}{ Importance } & \multicolumn{3}{|c|}{ Utility } \\
\hline & & included & $\begin{array}{c}\text { not } \\
\text { included }\end{array}$ & SD \\
\hline 1. Up-to-date service & $9 \%$ & -.052 & .052 & .319 \\
\hline 2. Travel preparation & $9 \%$ & -.060 & .060 & 291 \\
\hline 3. Navigation club & $10 \%$ & -.099 & .099 & .312 \\
\hline 4. Personalization & $8 \%$ & -.086 & .086 & .284 \\
\hline 5. Traffic information & $9 \%$ & 097 & -.097 & .297 \\
\hline 6. Safety alerts & $10 \%$ & .105 & -.105 & .359 \\
\hline 7. Location-based advertising & $8 \%$ & -.039 & .039 & .303 \\
\hline 8. Audio book & $13 \%$ & -.236 & .236 & .373 \\
\hline 9. Parking assistance & $9 \%$ & .087 & -.087 & 291 \\
\hline Constant & & 3.055 & & .986 \\
\hline Pricing & $15 \%$ & & & \\
\hline Low price ( $25 \%$ discount) & & .257 & & .445 \\
\hline Regular price & & -.039 & & .286 \\
\hline High price (plus 25\%) & & -.217 & & .399 \\
\hline
\end{tabular}

Model fit: Pearson's $R=.980$ ( $p<.0000)$. Kendall's tau $=.883$ ( $p<.0000)$. Kendall's tau=1.000 for holdouts.

The table shows the average utilities over 106 respondents. Respondents value enhanced services like traffic information, parking assistance and safety alerts in a positive way when included in bundles. The utilities for these three services are positive, which indicates that respondents appreciate these services when compensated for the subscription fees. The four supplementary services all have a negative utility, which implies that their usefulness does not outweigh the costs. This partly supports our first hypothesis: all supplementary services are valued as we hypothesized. However, this is not the case for the enhanced services. Only 3 out of 4 of the services are valued as we hypothesized.

Price is an important component in the perceived utility. As we hypothesized, people prefer low prices to high ones. Table 1 shows that the relative importance of most bundle attributes is close together, near 9\%. Bundle price discount can be seen to have the highest impact on perceived utility (15\%), followed by the 'audio-book' service. Given the low utility of audio-books, we find that including the audio-book service in the bundle for a monthly subscription fee of $€ 2$ has a relatively strong negative impact on the likelihood that users will purchase.

The third hypothesis was formulated based on our experiences in the pre-testing phase. Test group participants indicated that purchase intent not only depended on bundle composition and bundle pricing as such, but on budget considerations as well. This meant that people would rate larger bundles, with typically higher prices, relatively low because the bundle price exceeds the psychological maximum price that they associate with this type of services. We checked this in our analysis by correlating the (neutral) price of the presented bundles with their estimated perceived utility (corrected for price bundle discount utility). The correlation tuned out to be around -0.3, showing a significant negative budget effect, which means that we can accept this hypothesis. 
The next step was to determine preference clusters, which involved composing groups of people with similar part worth utilities for the services. We limited our analysis to three clusters. The cluster analysis was based upon the part worth utilities of the add-on services. The constant and the bundle price discount were not included in the analysis.

Table 2: Cluster statistics

\begin{tabular}{|c|c|c|c|c|c|c|c|}
\hline \multirow{3}{*}{ Services } & \multicolumn{6}{|c|}{ Clusters } & \\
\hline & \multicolumn{2}{|c|}{1} & \multicolumn{2}{|c|}{2} & \multicolumn{2}{|l|}{3} & \\
\hline & mean & sd & mean & sd & mean & sd & \\
\hline 1. Up-to-date service & $-0,066$ & 0,222 & 0,058 & 0,447 & $-0,162$ & 0,294 & $\begin{array}{l}\mathrm{F}=3.215, \\
\mathrm{df}(2,103), \\
\mathrm{P}<.05\end{array}$ \\
\hline 2. Travel preparation & 0,041 & 0,239 & $-0,110$ & 0,275 & $-0,247$ & 0,329 & $\begin{array}{l}\mathrm{F}=9.660, \\
\mathrm{df}(2,103), \\
\mathrm{P}<.001\end{array}$ \\
\hline 3. Navigation club & $-0,045$ & 0,293 & $-0,106$ & 0,316 & $-0,224$ & 0,330 & $\begin{array}{l}\mathrm{F}=2.680, \\
\mathrm{df} \quad(2,103), \\
\mathrm{ns}\end{array}$ \\
\hline 4. Personalization & 0,032 & 0,222 & $-0,166$ & 0,300 & $-0,276$ & 0,272 & $\begin{array}{l}\mathrm{F}=13.320 \\
\mathrm{df}(2,103) \\
\mathrm{P}<.001\end{array}$ \\
\hline 5. Traffic information & 0,105 & 0,237 & $-0,071$ & 0,294 & 0,298 & 0,315 & $\begin{array}{l}\mathrm{F}=11.726, \\
\mathrm{df}(2,103), \\
\mathrm{P}<.001\end{array}$ \\
\hline 6. Safety alerts & 0,007 & 0,210 & $-0,067$ & 0,211 & 0,577 & 0,417 & $\begin{array}{l}\mathrm{F}=44.402, \\
\mathrm{df}(2,103), \\
\mathrm{P}<.001\end{array}$ \\
\hline 7. Location-based advertising & 0,023 & 0,239 & $-0,300$ & 0,307 & 0,151 & 0,212 & $\begin{array}{l}\mathrm{F}=22.989, \\
\mathrm{df}(2,103), \\
\mathrm{P}<.001\end{array}$ \\
\hline 8. Audio book & $-0,027$ & 0,248 & $-0,567$ & 0,357 & $-0,321$ & 0,305 & $\begin{array}{l}\mathrm{F}=33.302, \\
\mathrm{df}(2,103), \\
\mathrm{P}<.001\end{array}$ \\
\hline 9. Parking assistance & 0,127 & 0,280 & $-0,006$ & 0,259 & 0,111 & 0,341 & $\begin{array}{ll}\mathrm{F} & =2.137 \\
\mathrm{df} & (2,103), \\
\mathrm{ns} & \\
\end{array}$ \\
\hline Constant & 2,964 & 1,093 & 3,211 & 0,815 & 3,076 & 0,923 & \\
\hline Average bundle utility* & 3,159 & & 1,877 & & 2,982 & & \\
\hline $\mathrm{N}$ & 55 & & 29 & & 22 & & \\
\hline & $52 \%$ & & $27 \%$ & & $21 \%$ & & \\
\hline
\end{tabular}

*: with all services included

Respondents in cluster 1 value enhanced services like travel preparation, traffic information, safety alerts, and parking assistance and supplementary services like personalization and location-based advertising. Other services devaluate their bundle. The total utility of the complete bundle is 3.0. When the negatively valued services are 
excluded from the bundle, total bundle utility increases to 3.4. Respondents in cluster 2 are only interested in updates of the navigation system. A bundle that includes the assumed basic navigation services and updates, and does not include all other enhanced and supplementary services is valued by them with 4.7 . Respondents that belong to the third cluster predominantly prefer enhanced services like traffic information, parking assistance and safety alerts. They also show an interest in location-based advertising, one of the supplement services. A bundle containing only these four services has a 5.4 utility rate.

If we take a closer look at the services included in the bundles, we see that none of the clusters is interested in the supplementary navigation communities (there are no significant differences between the three clusters) or audio books services. Of the other two supplementary services, location-based advertising are relevant to two clusters, and personalization is only relevant to respondents in the first cluster. Three out of the four enhanced services are relevant to two of the clusters. Travel preparation is relevant to one cluster only. None of the services is relevant to all three clusters. There appears to be a natural grouping of services. Updates are only valued by cluster 2 respondents. Traffic information, parking assistance (there are no significant differences between the three clusters), safety alerts, location-based advertising are appreciated by respondents in cluster 1 as well as cluster 3 . This reduces the choice from 9 services to 2 service bundles.

\section{Discussion and Conclusions}

We looked at the bundling of add-on services to existing core navigation services. In the conjoint analysis we used an orthogonal design, implying that only a main effect can be determined. A shortcoming of this approach is that it does not allow us to determine interaction effects between attributes. The utility of a certain service may, for example, depend on the presence of another service in the bundle. A limitation of the study is that it was carried out in the Netherlands, which is a small country were destinations are always near (driving times above two hours within the Netherlands are exceptional), and support facilities for traveling with cars are very good, which may mean that the need for specific enhanced and supplementary services may be lower. On the other hand, navigation systems are broadly accepted on the consumer market, which means that respondents are familiar with them. And although this study focused on the Netherlands in particular, we believe that our results have a broader validity.

With regard to our hypotheses, we may conclude that all three hypotheses are supported, although the support for the first one is not straightforward. Supplementary services are less attractive than enhanced services, which is as expected. However, not all of the four enhanced services are favored by the respondents. Our study shows a clear preference for service bundling of add-on services that directly enhance the navigation experience. Typical enhanced services are integrated traffic information and safety alerts. People appear willing to pay for these services, given the fact that we assumed a $€ 2$ per month subscription fee. Supplementary services are clearly much less appreciated. From a marketing point of view one may argue that providers may follow a mixed bundling approach in which the enhanced services are offered as a bundle and the support and supplementary services are offered separately. It is interesting to note that our analysis shows that the inclusion of 'location-based advertising' has little impact on the perceived utility of a bundle. A provider may therefore benefit from offering an advertising service without actually lowering people's appreciation of the bundle. As was expected, respondents prefer to pay a lower price over a higher price, which confirms our second hypothesis. However, the relative importance of the considerable price discounts is not much higher than the relative importance of bundle composition, which indicates that a careful composition of a bundle may have a greater positive impact on its perceived value than a simple price discount. 
The budget considerations that we encountered in the pre-test phase were confirmed during our analysis. There appears to be a psychological price ceiling above which people seem reluctant to go, which was as expected. Budget constraints probably play a role in the mental process of rating a bundle, i.e. it is not just a trade-off between bundle composition and price, but also whether one wants to spend a certain budget on a specific type of services.

As far as the research approach we used in this study is concerned, we feel that it helped us to conduct our research in an unobtrusive way, allowing us to map the preferences of potential users of future mobile services and service bundles.

\section{References}

Adams, W. \& J. Yellen (1976): Commodity Bundling and the Burden of Monopoly, Quarterly Journal of Economics, Vol. 90 (3), pp. 475 - 498.

Benett, R.J. \& Robson, P.J. (2001), 'Exploring the market potential and bundling of business association services', Journal of Services Marketing, Vol. 15 (3), pp. 222-239.

Bouwman, H. (2004): Any place, any where or the right place and the right time. $3^{\text {rd }}$ Generation Mobile Information and Entertainment studies. A vignette study. Paper presented to: ICA $54^{\text {th }}$ Annual Conference, New Orleans, May 27-31.

Bouwman, H. \& Wijngaert, L. van de (2002): Content and Context: A new research approach to the basic characteristics of information needs. New Media \& Society. Vol 4 (3) pp. 329-353.

Bouwman, H. \& Wijngaert, L. van de (2003): E-commerce in context: policy capturing and customer value. Paper presented to: 16th Bled Conference eTransformation, Bled, Slovenia, June 9 -11, 2003, pp. 974-986.

Bouwman, H., Faber, E. and T. Haaker (2005): Designing business models for mobile service bundles. Paper presented to: Hong Kong Mobility Roundtable, 1-3 June 2005, Hong Kong, China.

Brodt, T.\& M. Heitmann (2004): Customer centric Developemnt of Radical New Products. A European Case. Paper presented to: $10^{\text {th }}$ AMCIS conference, New York.

Chiasson, G. (1999): Bundle of Joy. Telephony Vol, 237, no 23, p. 42-46

Green, H.A.J. (1976), Consumer theory, London, Macmillan

Green, P. and Srinivasan, V. (1978): Conjoint analysis in consumer research: Issues and outlook, Journal of Consumer Research, vol, 5, September 1978, pp 103-123.

Harlam, B.A., A. Krishna, D.R. Lehmann, \& C. Mela (1995): Impact of bundle type, price framing and familiarity on purchase intention for the bundle, Journal of Business Research, 33:57-66

Kim, Y. (2004): Estimation of consumer preferences on new telecommunications services: IMT-2000 service in Korea. Information Economics and Policy. Vol. 17, p. 73-84.

Kleijnen, M., K. de Ruyter, \& M. Wetzels (2004): Consumer Adoption of wireless services: discovering the rules while playing the game. Journal of Interactive Marketing, Vol. 18, no.2, pp. 51-61.

Köhne, F. C. Totz \& K. Wehmeyer (2003): Consumer Preferences for Location Based Service Attributes. A conjoint analysis, pp. 115-127. In : G. M. Giaglis, H. 
Werthner, V. Tschammer \& K.A. Froeschl (eds.). The $2^{\text {nd }}$ international conference on Mobile Business. Wien: Östereichische Computer Gesellschaft

Kotler, P. (1999): Principels of Marketing. London: Prentice Hall Europe.

Martocchio, J., J., Webster, J., \& Baker, C., R. (1993): Decision-making in management information systems research: the utility of Policy Capturing methodology. Behaviour \& Information technology, 12(4), 238-248.

Mourdoukoutas, P. \& Mourdoukoutas, P. (2004), 'Bundling in a semi-global economy', European Business Review, Vol. 16(5), pp. 522-530.

Normann, R. (2001), Service management: Strategy and Leadership in Service Business, $3^{\text {rd }}$ edn, John Wiley \& Sons, Chichester, UK.

Pagani, M. (2004): Determinants of Adoption of Third Generation Mobile Multimedia Services. Journal of Interactive Marketing, Vol. 18, no. 3, pp. 46-59.

Penttinen, E. (2004): Bundling of Information Goods, Past, Present and Future. Helsinki School of Economics, Working Papers W-373.

Rossi, P. H., \& Anderson, A. B. (1982): The Factorial Survey Approach: An Introduction. In P. H. Rossi, \& S. L. Nock (Eds.), Measuring Social Judgments (pp. 15-67). Beverly Hills: Sage.

Schlesinger, B. (2003): Dynamic navigation systems: heading in the right direction; Boaz Schlesinger reviews the pros and cons of on and off-board navigation, Geo Connexion, 2003, 02, 01

Shapiro, C., \& H. Varian, (1999): Information Rules: A strategic guide to the network economy. Harvard Business School Press, Boston.

Simons, L. \& H. Bouwman (2004): Developing an Multi Channel Service Model and Design Method, International Journal of Internet Marketing and Advertisement, Vol 1, No. 3, pp 229-250.

Spiller, P.T. \& B.A. Zelner (1997): Product complementarities, capabilities and governance: a dynamic transaction cost perspective, downloaded from: http://faculty.haas.berkeley.edu/spiller/BUNDLICCa.pdf

Stremersch, S. \& G.J. Tellis (2002): Strategic bundling of Products and Prices: A new synthesis for marketing, Journal of Marketing, Vol. 66, no. 1, pp. 55-72.

Webster, J., \& Trevino, L. K. (1995): Rational and Social Theories as Complementary Explanations of Communication Media Choices: Two Policy-capturing Studies. Academy of Management Journal, 38(6), 1544-1572.

Wijngaert, L. van de (1996): A users' perspective on information services. In: Information services \& use, Vol. 16, Issue 2, pp. 103-122.

Wijngaert, L. van de (1999): Matching Media. Information Need and New Media Choice. Enschede: Telematics Institute, pp. 208.

Zhu, K. \& McQuarrie, B. (2003), 'The economics of digital bundling: the impact of digitization and bundling on the music industry', Communications of the ACM, Vol. 46 (9), pp. 264-270.

Zubey, M., W. Wagner \& J. Otto (2002): A conjoint analysis of voice over IP attributes. Internet Research, Viol. 1, No. 2, pp. 7-15. 